\title{
Interpretação - reprodução musical - teoria da performance: reunindo-se os elementos para uma reformulação conceitual da(s) prática(s) interpretativa(s)
}

\author{
Frank Michael Carlos Kuehn (UNIRIO, Rio de Janeiro, RJ) \\ performancetheorie@gmail.com
}

\begin{abstract}
Resumo: Notam-se nas ciências humanas enormes dificuldades na definição e no emprego dos conceitos que designam fenômenos culturais. Isso vale também para a área da música, onde costuma se notar certa confusão quando se passa para o entendimento do que designam os termos interpretação e performance. 0 presente ensaio quer responder a essa tarefa, urgente tanto do ponto de vista teórico quanto científico. Como a análise envolve a tradução e a transliteração de conceitos fundamentais de um idioma para outro, abordam-se primeiramente os critérios que norteiam a sua aplicação no contexto histórico da tradição musical clássico-romântica vienense. 0 objetivo central é demonstrar como esses conceitos diferem em sentido e fim. 0 próximo passo consiste numa análise criteriosa do conceito de reprodução musical. Por fim, propõe-se o trinômio reprodução musical, interpretação e performance como arcabouço conceitual para o ensino e a pesquisa da(s) prática(s) interpretativa(s). Ao mesmo tempo, o campo teórico da disciplina aumenta em sua abrangência migrando de uma noção embasada quase que unicamente na interpretação para a de um processo artístico multiforme de grande potencial produtivo e transformador que inclui também os elementos extramusicais da reprodução.
\end{abstract}

Palavras-chave: prática(s) interpretativa(s); teoria da interpretação; teoria da performance; tradição musical vienense; reformulação conceitual da(s) prática(s) interpretativa(s).

Interpretation - musical reproduction - theory of performance: bringing together the elements for a conceptual reform of the interpretative and the performance practice as a scholar discipline

Abstract: Great difficulties are noted in human sciences regarding the definition and use of the concepts designating cultural phenomena. This also stands good for the musical area, in which not often arise certain confusion when one moves to the understanding of what the terms interpretation and performance designate. The present essay aims to answer to this task, urgent both from the theoretical and from the scientific viewpoints. As the analysis involves the translation and transliteration of fundamental concepts from one idiom to another, we first approach the criteria guiding their application within the historical context of the classical-romantic Viennese musical tradition. The main objective is to demonstrate how these concepts differ in sense and end. The next step consists in a careful analysis of the concept of musical reproduction. Finally, the trinomial reproduction, interpretation and musical performance is proposed as a conceptual basis for teaching and research of the musical interpretative practice. At the same time, the theoretical field of the discipline increases in its scope, migrating from a basically interpretative concept to that of a multiform artistic process with great productive and transformational potential that also includes the extramusical elements of reproduction.

Keywords: interpretative/performance practice; theory of musical interpretation and of performance; Viennese musical tradition; conceptual reform of interpretative and performance practice. 
Todo o domínio da imaginação e da história, do passado e do futuro aguardam por seu gesto. Friedrich SCHILLER [1759-1805] (2009, p.10) ${ }^{1}$

\section{1 - Apresentação do problema}

É patente observar que a dimensão performativa da atividade artística está cada vez mais no centro das atenções, tendo conquistado também no meio musical cada vez mais espaço. Não raramente, porém, tem-se a impressão de que o termo performance poderia estar sendo empregado no lugar de "interpretação", o qual, por sua vez, é um termo tradicionalmente vinculado à academia, em particular à disciplina das práticas interpretativas, mas também à teoria e à filosofia da música (hermenêutica musical). Diferenciemos, portanto, de antemão, entre o termo "práticas interpretativas", no plural, e "prática interpretativa", no singular. 0 primeiro designa a disciplina acadêmica do mesmo nome, enquanto o segundo se refere à prática propriamente instrumental, tendo como base um texto musical ou partitura.

Sendo assim, lembro-me de ter acompanhado, há alguns anos, uma discussão sobre a questão de qual seria o termo mais adequado para designar a respectiva especialização na área da música. 0 episódio foi provocado por uma exigência da CAPES para que a terminologia técnicocientifica de áreas e subáreas empregada formalmente fosse atualizada. Discutiram-se, na época, opções mais na base do "ou...ou", isto é, no princípio da exclusão, do que no "e", de inclusão. Finalmente, optou-se por manter o termo "práticas interpretativas", o que fez surgir a pergunta sobre o que fez "a academia"2 recuar da tentativa de se incluir a performance como especialidade da área. Também não me lembro de nenhuma declaração dada que incluísse uma definição conceitual ou justificativa das razões do porquê da determinação. Dai pode se concluir que muito provavelmente se subestimaram as consequências que tal decisão traria para a área da música, pois a conceituação técnico-formal se reflete também nos resultados das avaliações periódicas. De qualquer forma, o episódio mostra que a própria articulação da disciplina com vistas ao seu fortalecimento junto ao meio acadêmico e às agências de fomento continua a representar um desafio. Por outro lado, é preciso ponderar que a mera inclusão de uma nova subárea ou especialização seria inócua sem que se tenha uma clara definição e delimitação conceitual da mesma.

Pois bem, ora usados como sinônimos, ora apresentados em sentido trocado, ainda é habitual se notar certa confusão no emprego dos termos interpretação e performance. Se a falta de rigor talvez possa ser admitida no senso comum, em termos de uma teoria da interpretação ou da performance, ela se revela como fatal, pois para qualquer investigação que se pretende científica é indispensável que se definam, de maneira clara, os conceitos com base nos quais ela é edificada. Tal entendimento também é imprescindivel quando desejamos desenvolver estudos sobre um determinado problema, como é o nosso caso.
Urge, portanto, elaborar um fundamento conceitual mais sólido para a(s) prática(s) interpretativa(s). Também é preciso esclarecer uma série de incongruências que o emprego confuso dos termos "interpretação" e performance trouxe para a área. Creio, inclusive, que não seja exagero afirmar que a falta de uma fundamentação substantiva tenha sido um obstáculo no desenvolvimento de modelos teóricos mais consistentes para a disciplina.

Por outro lado, existe também uma produção científica significativa que reflete o estado avançado das performance studies no Brasil. Nesses termos, devo agradecimentos à produção de AMATO (2006), APRO (2006), BORÉM (2005, 2006), CHUEKE (2005), GANDELMAN (1996, 2001), GERLING/GUSMÃO (2005), LIMA (2005, 2006), RAY (2005) e ZANON (2006), entre outros. Sua leitura é fundamental e se recomenda tanto para introduzir quanto para complementar 0 assunto em pauta.

Uma análise de diferentes momentos da história mostra como o diálogo entre a criação musical (o compositor), a execução (o intérprete) e a produção intelectual ou filosófica pode ser fecundo. Um periodo extraordinário é, sem dúvida, o que se inicia, no século XIX, com Beethoven (1770-1828) na cidade de Viena e que se estende até os anos trinta do século $X X$, aproximadamente. Sabemos também que a prática de Schönberg ainda se apoiava no tripé teoria, composição e execução, esferas que se estimularam e se alimentaram mutuamente. Pensandose no Brasil, a Semana Moderna de 1922 revelou o compositor Heitor Villa-Lobos (1887-1959), entre muitos outros artistas, antes desconhecidos. Ao instituir 0 conceito de "antropofagia", a Semana Moderna de 1922 revolucionou o cenário artístico e intelectual brasileiro, que nunca mais foi o mesmo. Também o movimento Música Viva, liderado por Hans-Joachim Koellreutter (1915-2005) nos anos 1940, deixou as suas marcas muito além do círculo onde o movimento tinha se iniciado. ${ }^{3}$

Mas o que será que esses eventos históricos, tão distantes em tempo e espaço, têm em comum? Embora bastante agitado e não raramente conturbado, 0 diálogo entre artistas compositores, teóricos, críticos e filósofos sempre deixou grandes impactos na produção e no desenvolvimento da música, fazendo com que seus desdobramentos se projetassem para além do seu tempo e lugar. Nos exemplos históricos citados, o exercício da reprodução estava sempre vinculado ao da composição e ao da teoria musical. Além disso, o compositor também era o intérprete de sua própria obra (e vice-versa). Hoje, contudo, esse modelo está atrofiado porque reduzido quase que exclusivamente à reprodução ad infinitum de um repertório historicamente definido e delimitado. 
Com efeito, uma revisão da disciplina das práticas interpretativas se torna mesmo inevitável. Por negligenciar que a prática interpretativa constitui uma atividade essencialmente performativa, a ênfase do seu ensino está centrada num modelo exaurido que parece preferir formar meros reprodutores a músicosintérpretes completos (pede-se desconsiderar as exceções!). Depois de todos os avanços da pesquisa musicológica, não faz sentido revisitar a música histórica como quem simplesmente vai ao museu. É necessário recriá-la através de interpretações vivas que a tragam para a contemporaneidade. É no momento da sua reprodução que a composição passa por um processo de "atualização", cujo alcance ultrapassa em muito a noção de "interpretação". Daí também a necessidade de se designar e delimitar com mais rigor os elementos do processo performativo da transformação de imagem em som. Embora, durante muito tempo, esse aspecto tenha estado relegado pela pesquisa musicológica, é notório que a prática performativa do concertista e do regente demanda, além de conhecimento musical, também entendimento acerca da sua representação mímica e gestual no palco.

Uma vez que a universidade não forma para a performance, acredito ser desejável que disciplinas de conteúdo performativo também sejam oferecidas no âmbito do ensino das práticas interpretativas. Apesar dos esforços, o campo da performance musical ainda carece de fundamento teórico e conceitual e representa um aspecto que, na prática, costuma depender muito mais da intuição e do improviso do que propriamente da aquisição de conhecimento em cursos formais. Tais disciplinas compreenderiam os fundamentos de diferentes linguagens artísticas, como: expressão corporal, gestualidade musical, mímica, articulação vocal e, pontualmente, também elementos da produção cênica e visual. Logo, também iniciativas que promovam 0 intercâmbio entre compositores, músicos e intérpretes que atuam "no mercado" teriam um efeito extraordinariamente benéfico sobre a produção de conhecimento. Ainda que a universidade estivesse, desde o início, destinada para esse fim, é bom lembrar que não deve existir nenhum monopólio na geração de conhecimento.

Uma forma de se recuperar o elo perdido entre a produção prática e a teórica da música seria promover, de forma gradual, a integração de diferentes disciplinas de conteúdo teórico e de conteúdo prático. Em nosso caso, recomenda-se a integração de disciplinas teóricas da musicologia histórica e sistemática com as disciplinas de "criação" musical, como composição, harmonia, prática instrumental livre e execução instrumental (práticas interpretativas). Quanto aos benefícios concretos que tal medida poderia proporcionar, cito Aquino, o qual, em 2003, já tinha salientado que:

A integração entre composição e performance [leia-se práticas interpretativas] abre oportunidade para o intérprete não apenas estar em contato com novas linguagens, estilos composicionais e técnicas de notação musical, como também permite 0 desenvolvimento de aspectos técnico-instrumentais específicos para a interpretação deste repertório. Da mesma forma, vários conceitos desenvolvidos por musicólogos transformam-se em ferramentas fundamentais para as decisões interpretativas. Através da plena interação entre as subáreas de música poderemos formar intérpretes com melhor embasamento teórico, além de teóricos preocupados em oferecer soluções práticas para as mais diversas questões interpretativas (AQUINO, 2003, p.107).

Em adição às observações de Aquino, acredito também que uma formação musical sólida e abrangente se manifesta tanto na articulação de ideias quanto na produção propriamente musical (performance). Essa visão - embora de grande valia quando se almeja a excelência e a inovação em ensino e pesquisa - não representa absolutamente uma posição unânime e encontra ainda resistências. De qualquer forma, para se promover efetivamente uma mudança de paradigma nesse campo, seria necessário que a academia se desapegasse do seu espírito hermético e excessivamente conservador.

Por tudo isso, enseja-se que as reflexões e proposições elaboradas contribuam para o debate e que representem um passo na direção certa. Tendo como objeto de investigação o uso de conceitos fundamentais da própria prática da disciplina, o presente ensaio representa sobretudo uma auto-reflexão.

Uma vez que a investigação envolve a tradução e a transliteração de conceitos fundamentais de um idioma para outro, abordam-se primeiro os critérios que nortearam a sua aplicação no contexto histórico e cultural da tradição musical clássico-romântica vienense. 0 objetivo central é demonstrar como os conceitos interpretação e performance designam processos distintos e como diferem em sentido e fim. A meta é chegar a uma distinção conceitual bem clara e rigorosa. Nessa tarefa, principalmente o termo performance exigiu uma análise mais aprofundada. Tendo passado, nas últimas décadas, por uma espécie de dinâmica própria, foi necessário dissociar o seu emprego no Brasil daquele em países de língua inglesa.

0 passo seguinte consiste numa análise criteriosa do conceito de reprodução musical, empregado por Heinrich Schenker, Arnold Schönberg, Walter Benjamin e Theodor Adorno. Depois também se avalia uma eventual extensão da validade do(s) conceito(s) a outro(s) contexto(s) que não da música de concerto, desde que as circunstâncias configurem de fato uma situação de reprodução, de interpretação ou de performance musical.

Por fim, os conceitos reprodução, interpretação e performance musical serão reunidos para constituir um fundamento distinto e, ao mesmo tempo, mais abrangente da(s) prática(s) interpretativa(s).

Para se delimitar a investigação, formulamos ainda três pressupostos de grande alcance: 1) que, em nosso contexto, o termo reprodução não se refere a nenhuma reprodução 
mecânica; 2) para que se fale de "interpretação", "reprodução" ou de performance admitimos a existência de um texto ou partitura que permita que uma composição possa ser reproduzida musicalmente; 3) distinguimos, portanto, duas grandes categorias de música: a de tradição escrita e a de tradição oral.

\section{2 - Interpretare e interpretação}

Comecemos a investigação com o termo mais antigo. "Interpretação" designa, em música, a leitura singular de uma composição com base em seu registro que, representado por um conjunto de sinais gráficos, forma a imagem de texto ou partitura. Ao decodificar os sinais gráficos do texto, o músico transforma ideias de maneira mais fiel em som, interpretando-as. Desse modo, "interpretar" está intimamente ligado à compreensão prévia da obra pelo músico-intérprete. Segundo DOURADO (2004, p.169), a etimologia do termo interpretação remonta à Antiguidade greco-romana. Presume-se que o verbo latino interpretare tenha a sua origem na expressão inter petras, que significa algo como "entre-pedras".

Considerando-se a partitura musical uma espécie de "roteiro" ou "mapa" para se chegar, por assim dizer, ao "tesouro" ou à "verdade" da obra, a interpretação corresponde à tarefa de trazer à luz não apenas o que está escrito, mas também (ou principalmente) o que está entre as indicações grafadas na partitura. Heinrich SCHENKER $(2000$, p.5) chama atenção para esse detalhe, pois "o mero fato de que a nossa notação dificilmente represente mais do que neumas deve fazer com que 0 intérprete procure o sentido por trás dos símbolos".

Antes que a música interpretada possa ser compreendida pelo público, é mister que o concertista, o instrumentista, o vocalista ou o regente se aproxime do pensamento musical de seu compositor (KAPP, 2002, p.458). "Saber interpretar", por conseguinte, implica, no contexto da música de concerto, uma espécie de "musicologia aplicada", na qual o acesso à "essência" ou "verdade" não é espontâneo ou acontece via intuição direta e sim por meio de uma postura refletida e ponderada, estando sempre acompanhada por conhecimento tanto teórico quanto empírico (GRASSL; KAPP, p.xix). Em suma, a prática interpretativa é uma atividade transformadora que exige do músicointérprete além de dedicação e responsabilidade também máxima compreensão e saber específico.

Diante da carência de material teórico e para oferecer subsídio técnico aos intérpretes, Richard Wagner (18131883), Heinrich Schenker (1868-1935), Arnold Schönberg (1874-1951), Rudolf Kolisch (1896-1978), Frederick Dorian (1902-1991) e, finalmente, também Theodor Adorno (1903-1969) desenvolveram diversas teorias. Dessas teorias, particularmente a de Adorno revela uma face ainda pouco conhecida desse autor, que parece estar no fim de um ciclo extraordinariamente fecundo e produtivo da tradição estético-filosófica de língua alemã.

\section{3 - Os termos Vortrag, Aufführung e "reprodução musical"}

Em sua grande maioria, os autores pesquisados empregaram os composita germânicos Vortragslehre (de Lehre, ensinamento, teoria + Vortrag, apresentação, exposição, discurso, palestra), Aufführungslehre ou Lehre der musikalischen Aufführung (evento artístico, apresentação de uma obra de arte cênica ou musical no palco), Ausführung (execução), assim como Wiedergabe e/ou Reproduktion (reprodução, sendo o primeiro o correspondente germânico do segundo, de raiz latina).

Enquanto a aplicação do termo Vortrag ao campo da música representa uma ampliação do seu domínio original (antes restrito à apresentação de discursos ou palestras), o termo Aufführung abrange praticamente todo tipo de representação artística ao vivo no palco. Por conseguinte, os termos Vortragslehre e Aufführungslehre circunscrevem, em música, o campo do saber que se ocupa sistematicamente dos processos que envolvem a transformação do texto em som e suas técnicas. Tal campo consiste, de um lado, na elaboração teórica, voltada para a análise formal e a composição e, de outro, na aplicação prática que enfoca a execução de uma determinada obra musical (GRASSL; KAPP, 2002, p.ix).

Richard Wagner, por exemplo, emprega os termos Vortrag e Aufführung da seguinte forma: Vortrag, quando afirma que, "desde Beethoven, ocorreram mudanças substanciais a respeito do entendimento e da apresentação musical" (ao se referir ao modo de apresentação de uma determinada orquestra, Wagner ocasionalmente também usa o termo Orchestervortrag), e Aufführung, ao se referir a "uma performance pública da Abertura de Egmont" (WAGNER, 1953, p.78, 97 e 110), à qual tinha assistido. ${ }^{5} 0$ contexto das citações exemplifica bem a aplicação distinta dos termos: com Vortrag, Wagner se refere à prática interpretativa e às mudanças que, desde Beethoven, ocorreram no modo da execução musical, enquanto, com Aufführung, ele se refere ao concerto como evento social, muito próximo ao que hoje se entende nos países de língua inglesa por performance.

Também Schenker e Schönberg usaram originalmente o termo Vortrag para se referir à apresentação musical no palco. Em consequência das circunstâncias históricas e da ação direta de seus discípulos, a recepção da obra de Schenker se deu notadamente nos EUA, onde contribuiu para o desenvolvimento da teoria musical. ${ }^{6}$ Esse fato também explica por que a primeira publicação inédita da obra de Schenker após a sua morte ocorreu em inglês e não em alemão. Concebida por Schenker em 1911, foi publicada apenas em 2000, sob o título The art of performance [ $A$ arte da performance]. Schenker, no entanto, originalmente havia previsto o título: Die Kunst des Vortrags [ $A$ arte da exposição musical]. Reconhecido, sobretudo, por suas análises de obras-primas do repertório da tradição musical clássico-romântica, essa talvez seja a sua obra 
menos conhecida. Originalmente, Schenker tinha a intenção de dedicar $A$ arte da performance ao músicointérprete, em especial ao pianista, que considerava mais suscetivel do que os demais instrumentistas de incorrer em uma interpretação equivocada. Schenker pretendia remediar a precariedade da situação de outrora com regras gerais e orientações técnicas acerca da interpretação. Infelizmente, Die Kunst des Vortrags permaneceu um projeto inacabado, porque 0 seu autor preferiu se dedicar a outros títulos da sua considerável produção teórica.

Tudo indica que o emprego do termo "reprodução" (Reproduktion, Wiedergabe) aplicado à música tenha ocorrido pela primeira vez com Schenker. Ao criticar o papel que a reprodução musical ocupava no meio musical, "em flagrante contraste com as verdadeiras origens", SCHENKER (2000, p.4) reivindicou uma "reprodução verdadeira".7 Isso, no entanto, é uma hipótese que se apoia na suposição - aliás, muito provável - de que Schenker tenha recorrido ao termo de raiz latina Reproduktion, o que apenas pode ser verificado com segurança em uma análise do manuscrito original. De qualquer forma, nos Estados Unidos, os termos germânicos Vortrag e Aufführung já aparecem traduzidos como performance.

Nota-se que, assim como Schenker, também Schönberg se queixou dos exageros cometidos por intérpretes de seu tempo: "Deve-se ter na devida conta que [...] muitos artistas exageraram ao exibir com toda a intensidade as emoções que eram capazes de sentir [...] artistas que se acreditavam mais importantes do que a obra - ou, pelo menos, do que o compositor" (SCHÖNBERG, 1984, p.321).8 Talvez seja por essa razão que Schönberg parece querer evitar (a todo custo?) os termos "intérprete" e "interpretação". Em seu lugar, prefere recorrer ao termo Ausführender, que se poderia traduzir como "executante" ou "executor", e, correlativamente, também a Ausführung, isto é, "execução". Explica-se: para Schönberg, um bom "executor" ou "bom executante" deve servir à obra, e não o contrário. Assertou ainda o compositor: "Um executante inteligente, que seja realmente 'um servidor da obra', alguém cuja agilidade mental seja equivalente à de um pensador da música tal pessoa procederá como Mozart, Schubert ou outros" (SCHÖNBERG, 1989, p.116). ${ }^{9}$

Sabe-se que, mesmo no exilio, Schönberg redigia seus ensaios em língua materna, para estes depois serem traduzidos para o inglês. Desse modo, os termos musikalischer Vortrag e Aufführung aparecem também em Schönberg traduzidos como performance. É, no entanto, curioso notar que também Schönberg recorreu ao termo "reprodução musical". Num dos ensaios em que disserta sobre a prática interpretativa, o termo aparece logo na abertura: "0 principio mais elevado de toda a reprodução musical está naquilo que o compositor escreveu [devendo ser tocado] de tal forma que cada nota possa ser escutada nitidamente"
(SCHÖNBERG, 1984, p.319). ${ }^{10} 0$ manuscrito, de pouco mais de uma página apenas, é datado de "1923 or 1924". Intitulado For a treatise on performance [Para um tratado sobre a performance], seguem-se a ele diversos outros ensaios nos quais o vienense aparentemente quis esboçar as diretrizes do seu projeto de elaborar uma teoria de execução musical. Com exceção de um único ensaio, todos são do período anterior à época em que ele se afastou de Viena, tendo a sua publicação ocorrido apenas postumamente (SCHÖNBERG, 1984, p.319-362). ${ }^{11}$ Com efeito, de certa forma intriga que também Schönberg não tenha concluído o seu projeto de elaborar uma teoria da execução musical.

Recorrente desde o século XVIII até a virada para 0 século XX, aproximadamente, o termo Vortrag aplicado à apresentação musical caiu em desuso nas décadas seguintes. Rudolf Kolisch, cunhado de Schönberg e de uma geração mais jovem que a deste, preferiu usar, em seus trabalhos teóricos, os termos Aufführung e Aufführungslehre (embora tenha recorrido, ocasionalmente, também ao termo Vortrag). A partir do exílio de Kolisch, também nos Estados Unidos, o termo Aufführungslehre passou a ser traduzido por theory of performance (teoria da performance). Do projeto original da teoria da performance - não concluida - foram publicados até agora apenas alguns poucos ensaios e uma entrevista (vide KOLISCH, 1983).

Ao publicar um estudo historiográfico sobre a prática interpretativa, também o vienense Frederick Dorian pianista, musicólogo e membro do círculo de Schönberg contribuiu para o tema. ${ }^{12}$ Sua obra, intitulada The history of music in performance [ $A$ história da performance musical] e publicada em 1942, disponibiliza uma grande quantidade de informações sobre a história da prática interpretativa desde o Renascimento italiano até 0 século XX. Desse modo, serviu também de referência para Adorno, para quem o livro de Dorian representou uma valiosa fonte em suas pesquisas acerca do assunto (ADORNO, 2005, p.333, nota 20).

Como podemos notar, a adaptação dos termos germânicos Vortragslehre e Aufführungslehre para "teoria da performance" levou a uma ampliação considerável do conceito original, passando agora a estender-se à apresentação, à execução, à realização, ao funcionamento e às condições internas e externas da representação artística como um todo (KAPP, 2002, p.458).

Os críticos desta concepção, entretanto, costumam argumentar que o elemento performativo tem servido, com seu apêndice mediato e midiático moderno, mais para o próprio intérprete dar-se a conhecer e promover suas habilidades de virtuoso do que para reproduzir uma determinada obra com fidelidade. Esse ponto, aliás, já expõe a primeira cisão entre uma concepção predominantemente interpretativa, e outra, performativa da reprodução musical. 


\section{4 - 0 conceito de "reprodução musical" de Walter Benjamin e de Theodor Adorno}

$\mathrm{Na}$ segunda metade do século XIX e nas primeiras décadas do século $X X, 0$ desenvolvimento da maquinaria industrial e o aumento da capacidade de reprodutibilidade técnica foram vertiginosos, constituindo um assunto controverso que ocupava o centro de debates acalorados, todavia no campo das ciências humanas. Para citar apenas dois exemplos distintos: Sigmund Freud (1856-1939) se referiu, nos primórdios da teoria psicanalítica, no Entwurf einer Psychologie (Projeto de uma psicologia, 1895), texto em que se acha boa parte das ideias posteriormente desenvolvidas por ele, a uma psicologia more apparatu (psychischer Apparat), isto é, à ideia de uma psique que funciona como uma aparelhagem neuronal (FREUD, 1987, p.375-477, em particular 398, 400, e 405-407). Também o conhecido (e ainda atualíssimo) ensaio de Walter Benjamin (1892-1940), publicado em 1936 e intitulado A obra de arte na era da sua reprodutibilidade técnica (Das Kunstwerk im Zeitalter seiner technischen Reproduzierbarkeit) deve ser compreendido nessas circunstâncias históricas.

Com o aperfeiçoamento das tecnologias em diferentes suportes de gravação, não apenas a composição como também a interpretação se tornaram reprodutíveis, podendo, destarte, passar a constituir um novo objeto da investigação musicológica. Por conseguinte, a possibilidade concreta de comparar diferentes intérpretes em categorias como individualidade artística, fidelidade histórica e expressividade musical em áudio e vídeo teve um impacto enorme em praticamente todas as esferas sociais e permitiu que o status de obra de arte se estendesse também à reprodução mecânica de uma composição. Em suma, o estudo da prática interpretativa como categoria de análise técnica e da historiografia da música configura uma descoberta do século XX e se revela de mais alta importância para a pesquisa musicologia (GRASSL; KAPP, 2002, p.xvii, xviii, xx).

Por razões que envolvem circunstâncias históricas, a influência do amigo Walter Benjamin ${ }^{13}$ e fatores de ordem conceitual, Theodor Adorno preferiu adotar, em sua teoria, o termo "reprodução musical". Empregado por Adorno num grande número de fragmentos e manuscritos redigidos, aproximadamente, entre 1925 a 1965, o termo "reprodução musical" pode ser definido, de forma elementar, como a realização sonora de uma obra musical com base em sua partitura, a qual, por sua vez, representa algo como a "imagem do som". Oriundos do espólio do autor, esses manuscritos foram editados na Alemanha sob o título Zu einer Theorie der musikalischen Reproduktion [Para uma teoria da reprodução musical] (ADORNO, 2005 [2001]). ${ }^{14}$

0 primeiro registro do emprego do termo "teoria da reprodução musical" por Adorno data de 1925, quando seu autor tinha apenas 23 anos de idade. Com efeito, o parágrafo inicial de um de seus primeiros artigos para 0 periódico musical vienense Pult und Taktstock [Púlpito e batuta], intitulado Zum Problem der Reproduktion [Acerca do problema da reprodução] (ADORNO, 2003, v.19, p.440444), termina da seguinte forma:

De que maneira pode a leitura de uma obra revelar o grau de liberdade que ela proporciona para o intérprete que a executa - isto me parece a tarefa central de uma teoria da reprodução, a qual, entretanto, como teoria, não poderia penetrar o que se funde indissoluvelmente em sua configuração e que, em sua plenitude, envolve o imitador como homem inteiro (ADORNO, 2003, v.19, p.441). ${ }^{15}$

Dadas a adoção definitiva do termo e a necessidade de uma elaboração teórica sobre o assunto, nas palavras condensadas que acabamos de ler já despontam algumas das premissas com base nas quais Adorno definirá a sua teoria nas décadas seguintes: 1) que a leitura de uma obra musical é uma interpretação; 2) que a interpretação implica certa liberdade, cujos limites de autonomia ainda precisam ser definidos; 3) que o conceito de "reprodução musical" envolve, de maneira indissociável, o intérprete, a obra e sua interpretação; 4) que o executante de uma obra musical é, além de intérprete, um "imitador" (Nachbildner); ${ }^{16}$ 5) que a reprodução musical proporciona plenitude; e 6) que a reprodução musical envolve também aspectos de integralidade humana, ou seja, questões de ordem ética, política e social. Tudo isso - vale ser reiterado - "como teoria não poderia penetrar o que se funde indissoluvelmente em sua forma".

É, contudo, importante distinguir, de forma inequívoca, o conceito de "reprodução musical" de Adorno do conceito de "reprodutibilidade técnica" de Benjamin, que denota as diferentes técnicas para reproduzir cópias de uma obra de arte a partir de um original, molde ou modelo em suportes mecânico-industriais. Já o conceito adorniano designa a reprodução in loco de uma obra musical, embasada no seu registro em forma de texto ou partitura. Benjamin escreveu, em seu ensaio: "À mais perfeita reprodução falta sempre algo: 0 hic et nunc da obra de arte, a unidade de sua presença no próprio local onde se encontra. É a esta presença, única, portanto, e só a ela, que se acha vinculada toda a sua história" (BENJAMIN, 1980, p.7, na tradução de J. L. Grünewald). É, portanto, justamente esse elemento como disse Benjamin, indispensável a toda obra de arte - que se encontra incorporado no conceito adorniano de reprodução musical. Diferentemente da denotação mecânica que o termo adquiriu com o aperfeiçoamento tecnológico dos suportes industriais e dos meios de comunicação de massa, o conceito adorniano acolhe exatamente o elemento hic et nunc em que uma composição é reproduzida pelo músico-intérprete. Por conseguinte, tratando-se da "leitura personalizada" de um texto, o conceito de reprodução musical abarca também a interpretação. Tendo etimologicamente a mesma raiz, tem a grande vantagem de denotar, nos idiomas português, alemão (Reproduktion) e inglês (reproduction), um significado muito semelhante. 


\section{5 - Do "ato performativo" da filosofia} da linguagem de Austin para a "guinada performativa" no campo da música

0 campo de pesquisa interdisciplinar conhecido como performance studies constitui atualmente um ramo de conhecimento que se materializou em número considerável de pesquisas e de publicações, seja na forma de novas abordagens da história, seja em reedições ou lançamentos de obras que tratam do assunto. Uma prova disso é a tradução inglesa da Teoria da Reprodução Musical [Towards a theory of musical reproduction], de Theodor ADORNO (UK, 2006), disponibilizada em tempo recorde se comparado com os noventa anos que o compêndio de Schenker levou para ser traduzido e publicado. A tradução possibilitou também que a Teoria da Reprodução Musical fosse debatido em âmbito internacional. Assim está com a conferência intitulada "Formulate with the greatest care: Adorno and performance" (Formulado com o máximo de cuidado: Adorno e a performance), patrocinada pelo Northern Royal College of Music, Manchester, UK, em 2008. ${ }^{17}$ Os outros trabalhos de cunho teórico dos autores nomeados na primeira seção, contudo, receberam até hoje pouca atenção - o que, a rigor, constitui uma contradição quando comparado com o grau da disseminação internacional do repertório da tradição musical vienense e da reputação de seus autores. Dai penso que o colóquio internacional, intitulado "A teoria da performance na Escola de Viena" [Aufführungslehre der Wiener Schule] e realizado, em 1995, na cidade de Viena, represente algo como o marco fundamental dos estudos musicológicos sobre o assunto. Também a publicação da coletânea de ensaios e pesquisas, organizada por Rink (2006 [2002]), representa um marco para os performance studies. Intitulada Musical performance, os autores dissertam sobre um determinado problema ou categoria específica da área, ao mesmo tempo em que buscam consolidálos em termos conceituais e metodológicos (cf. CLARKE, 2006; DAVIDSON, 2006; DUNSBY, 2006; REID, 2006).

Enquanto a definição dos termos "reprodução" e "interpretação" não apresentou maiores dificuldades, a noção de performance tem resistido a uma definição satisfatória na área da música. Foi na segunda metade do século XX que esse termo começou a disseminar-se maciçamente no campo musical - quiçá também em decorrência da emigração numerosa de compositores, intérpretes e intelectuais de língua alemã para os Estados Unidos..$^{18}$ Paralelamente, a conotação do termo performance ampliou seu campo de abrangência, propagando-se em diferentes áreas do saber, da filosofia ao esporte. Por tudo isso, o termo requer ainda mais esclarecimentos acerca da função e do significado dentro e fora do âmbito estritamente musical.

Enquanto, no esporte, o significado do termo performance pode ser sintetizado na ideia de eficiência que maximiza rendimento e desempenho físicos do atleta, na filosofia os estudos de performance remontam ao britânico John
Langshaw Austin (1911-1960), o qual, como filósofo da linguagem, elaborou uma "teoria dos atos de fala" (speech-act theory), em que aproxima elementos da linguistica e da filosofia da linguagem. Também chamada de linguistic turn ou "virada linguística", Austin parte da ideia de que nós não apenas procuramos reproduzir, por meio da linguagem ou discurso, o mundo ao nosso redor, mas também de que a própria linguagem é capaz de criar, por intermédio de determinadas enunciações, fatos novos que, de alguma forma, incidem sobre a realidade do nosso mundo social (assim, por exemplo, ocorre numa cerimônia de casamento, quando o casal é declarado marido e mulher). As palavras enunciadas, portanto, não são necessariamente uma mera consequência do mundo que nos cerca. Também é possivel o mundo social constituir-se de acordo com os nossos enunciados. É por meio dessa hipótese que surge para Austin a questão central sobre a qual versam suas investigações: o que exatamente acontece no momento "ato performativo" da fala (speech-act)? 0 postulado de Austin - e aqui se verifica semelhança surpreendente com a concepção da música como linguagem - é que a linguagem se fundamenta em si mesma. As questões colocadas por Austin, todas de suma importância, foram posteriormente retomadas pela filosofia contemporânea (Habermas, Searle, Derrida), pela linguistica (Chomsky), pela teoria da comunicação (Moles), assim como por diversas outras áreas, entre as quais as ciências sociais e políticas, as artes cênicas, a música e a literatura (AUSTIN, 1975; HETZEL, 2004, p.132-133; FISCHERLICHTE, 2004, p.22-30).

Embora tenha se referido originalmente ao contexto linguístico e filosófico das circunstâncias de fala, o ato performativo de Austin compartilha com a prática interpretativa da música uma série de afinidades e similitudes. Uma seria que haveria uma espécie de atração entre elas, a qual teria possibilitada que tal "guinada" ou "despertar" performativo pudesse ocorrer também no campo da música. Para se chegar a um denominador em comum, tentemos agora chegar ao princípio ativo do processo performativo. Faremos isso por meio da seguinte equação conceitual:

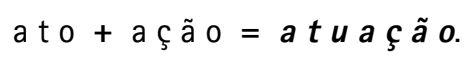

0 resultado nos remete a outro elemento chave da performance artística: à representação cênica e à atuação, ou seja, ao ator, ao mímico e sua mímica. Desvelamos, por assim dizer, a extraordinária amplitude do significado que a relação (simbiótica) do elemento mimético-gestual engendra na arte da música. Para evocá-lo, recordemos a sentença do dramaturgo e esteta Friedrich Schiller, posta no início deste trabalho: "Todo o domínio da imaginação e da história, do passado e do futuro aguardam por seu gesto" - só que agora em correspondência com um enunciado de Theodor ADORNO, em cuja Teoria da Reprodução Musical (2005) o elemento mimético ocupa uma função central (quanto ao aspecto especificamente mimético da teoria de Adorno, vide também KUEHN, 2012): 
A relação entre mímica e música, central, torna-se evidente na esfera da reprodução [...] A música é mímica na medida em que [...] determinados gestos resultam em som musical. A música é, por assim dizer, a objetivação acústica da mímica facial, a qual, de certa forma, ter-se-ia separada daquela historicamente (ADORNO, 2005, p.206, 237)..$^{19}$

Daí seria a princípio lógico concluir que a leitura em silêncio de uma obra musical não poderia, em hipótese alguma, constituir uma performance, não fossem certos paradoxos que rompem com paradigmas estéticos tradicionais. Um desses paradigmas é, sem dúvida, o de sujeito e objeto. 0 compositor John Cage (1912-1992), discipulo estadunidense de Schönberg, seguramente detém o mérito de ter apontado alguns desses paradoxos. Além disso, é lembrado por sua contribuição do elemento performativo na música de concerto (KAPP, 2002, p.460468; FISCHER-LICHTE, 2004, p.24).

Composições e concertos de Cage evidenciam principalmente o enorme potencial crítico e social do ato performativo. Ao levar o próprio ato de reprodução musical ad absurdum, a performance de Cage questiona o paradigma tradicional de interpretação e mesmo o de "concerto", que chega a inverter. Assim ocorre com a composição de 1952, intitulada de $4^{\prime}$ 33". 0 número no título indica exatamente o tempo em que o (ou a) pianista (ou outro instrumentista ou formação de conjunto) deve, durante os três movimentos da peça, permanecer sentado(a) junto ao seu instrumento, sem, porém, tocar uma nota sequer. ${ }^{20}$

Nesse sentido, cabe lembrar outra vez Arnold Schönberg, para quem a performance (ou Aufführung) existe apenas na medida em que ela efetivamente facilite ou em que ela represente um obstáculo na sua compreensão. Para se esclarecer bem as posições: apesar de ter reconhecido a importância de uma interpretação correta ou adequada, o processo de criação de uma obra musical termina para Schönberg precisamente com a confecção da partitura. A reprodução representa para ele (que é compositor) algo supérfluo e, quando ela ocorre, o intérprete é visto como um mero "executante" ou "executor" da partitura. Daí que, para Schönberg, objetividade e clareza representem atributos absolutamente centrais para a interpretação. Tal posicionamento leva Schönberg a outro questionamento: "Is performance necessary? Not the author, but the audience only needs it" (apud KOLISCH, 1983, p.9). Continuemos com o compositor: "A interpretação é necessária para preencher a lacuna entre a idéia do autor e o ouvido contemporâneo, [e depende] da habilidade de assimilação do ouvinte em seu tempo" (SCHÖNBERG, 1984, p.328). ${ }^{21}$

Uma hipótese seria que Schönberg estaria respondendo a seu conterrâneo Schenker, pois este, conhecido por suas posições radicais, tinha, já em 1911, anotado:

Basicamente, a composição não precisa da performance para existir. A leitura silenciosa de uma partitura já é suficiente para provar a sua existência; basta o som surgir de forma apenas imaginada na mente. A realização mecânica de uma obra de arte musical pode, desse modo, ser considerada supérflua" (SCHENKER, 2000, p.3). ${ }^{22}$
Em contrapartida, para Cage, o ciclo da criação de uma obra musical se fecha apenas com a performance. Esse é o cerne que diferencia (e distancia) Cage e outras concepções contemporâneas das de Schenker e de Schönberg. De qualquer forma, é curioso observar que aqui parece se radicalizar um ponto de vista que antes já defenderam arautos do romantismo, como os compositores Liszt e Wagner (KAPP, 2002, p.456-457 e 461).

Até meados dos anos 1970, aproximadamente, os estudos culturais estavam centrados sobretudo em questões acerca da textualidade e da compreensão (hermenêutica) dos mesmos (o que, na prática, significava que obra e texto se confundem). Nas décadas subsequentes, contudo, as pesquisas acadêmicas passaram a focalizar a performance como evento artístico e social. Enfim, foi como evento sociocultural que a performance pôde se tornar uma categoria de pesquisa da antropologia social e da etnomusicologia ("fato social" ou "fato sonoro").

Destaca-se ainda a tendência que vê na performance uma fonte inesgotável de experiência, isto é, de vida (ou de vivência) e do corpo (embodiment). ${ }^{23}$ Outra tendência usa 0 ato performativo como uma ação que age criticamente sob o ambiente social ou natural, muitas vezes com o objetivo de se apontar determinados padrões de comportamento condicionados socialmente, encenando-os para, destarte, expor seus aspectos paradoxais. Em suma, na medida em que estavam se questionando paradigmas estéticos focados na relação de sujeito e objeto, despertou-se também para o potencial extraordinário da performance como instrumento de intervenção artística, política e social (FISCHER-LICHTE, 2004, p.15-22, 29, 153).

Performance, portanto, em música, nos remete em primeiro lugar à presença física no palco, ao corpo e à voz, não apenas com relação a determinadas técnicas de execução no instrumento e sim também como meio e como modo de interagir com o público espectador. Seus elementos ativos estão, sobretudo, na representação gestual de quem está "tocando" uma composição musical, ou seja, no intérprete, na quironomia do regente, na mímica e nos movimentos biomecânicos com suas técnicas e "escolas" (regionais ou nacionais) particulares.

Muito parecido com o que acontece no campo da música, observa-se também nas artes plásticas e nas artes visuais uma tendência para ações performativas que ocupam o espaço público criticamente (happening, environment, action painting ou body art). Nisso, esses eventos não raramente se transformam em espectáculos amplamente divulgados pela mídia.

Já nas artes cênicas, o conceito de performance está associado mais ao movimento e à representação mímicogestual do ator no palco do que propriamente ao conteúdo de seus enunciados, em geral sob a égide da interpretação. Do ponto de vista da indústria cultural, ou seja, do 
entretenimento e da cultura de massa, não é bem a interpretação e os seus enunciados o que mais importa, mas a performance - isto é, o show. Esse fato mostra claramente que existem gêneros musicais em que predomina a "arte da performance", ao passo que o conteúdo musical figura em segundo plano. Seja como for, se é também um bom performer, o intérprete está empenhado em "convencer" com a sua performance não apenas de forma instrumental e sim também visual, isto é, mímico-gestual. Considerando-se que se sabe ainda relativamente pouco sobre o real efeito que a música exerce no homem e no meio ambiente, o músico-intérprete precisa estar preparado não apenas tecnicamente como também em termos de ética para poder explorar todos esses recursos de forma "sustentável".

Tudo o que foi dito para definir e delimitar o campo conceitual da performance se torna ainda mais evidente no caso do circo, onde acrobatas, malabaristas e outros artistas se empenham (e triunfam) em suas performances, caso em que não se pode falar em interpretação. Também nos megaeventos da música pop percebemos a predominância de elementos performativos, em que todo tipo de luzes e imagens, os "efeitos multimídia", lembram mais um espetáculo circense do que uma interpretação propriamente dita. Por tudo isso, o emprego do termo performance precisa de mais ponderação quando aplicado a aspectos distintos da prática musical.

\section{6 - Reunindo-se os conceitos de reprodução, interpretação e performance num trinômio de grande abrangência}

Vemos que a opção de diferentes autores pelo termo "reprodução musical" não se deu por acaso. Essa opção também se mostra mais adequada para nós, porque assim ela nos permite lhe atribuir tanto a interpretação quanto a performance como princípios ativos. Visto desse modo, o momento da reprodução musical é também o da performance, assim como o da interpretação de uma composição. Noutras palavras, concebendo-se a reprodução musical como um processo dinâmico de grande alcance, os elementos de interpretação e de performance se transformam em categorias com que o evento artístico possa ser analisado e avaliado criticamente.

Obtivemos, desse modo, uma espécie de arcabouço conceitual da(s) prática(s) interpretativa(s). A premissa central é que o processo reprodutivo da música ocorre por basicamente duas vias: a ) pela interpretação, e b) pela performance. Sendo assim, os conceitos de reprodução, de interpretação e de performance se acham integrados num trinômio, podendo servir de base para uma grande gama de pesquisas e de considerações teóricas acerca da prática musical.

A vantagem da integração do conceito de performance está na ampliação substancial do modelo tradicional, a partir do qual nós somos levados a migrar de uma noção embasada quase que unicamente na "interpretação" para a de um processo artístico multiforme que inclui também os elementos extramusicais da reprodução. Logo, a realização efetiva de uma reprodução musical implica a performance, assim como ad litteram também a interpretação de uma composição musical.

0 trinômio alude também a três elementos absolutamente fundamentais da prática musical: 1) ao mimético da reprodução; 2) ao compreensivo e contemplativo da interpretação; e 3) ao performativo, donde a ideia do gesto, da encenação e do espetáculo. Sendo a categoria da reprodução a mais abrangente, abarca em si também as outras.

De um lado da figura, situemos os elementos intramusicais que estruturam a obra musicalmente, enquanto, de outro, situemos os elementos extramusicais que põem o músicointérprete literalmente "em cena", ou seja, em evidência. Esse é também o momento em que a composição é "atualizada" tanto estética quanto socialmente (a música como aglutinador de identidade social).

Desse modo, restaura-se, por assim dizer, no momento da reprodução, uma espécie de campo agonal em que as forças musicais da composição (rítmicos, harmônicos, dinâmicos, elementos estruturais etc.) interagem com a materialidade corporal e gestual da performance, do ambiente social e natural (acústico, por exemplo) do local da reprodução.

Empregado em separado, nenhum outro conceito faria jus à abrangência que o conceito de "reprodução musical" instaura, pois: 1) o termo "execução" implica algo mecânico que não leva em conta o aspecto lúdico e criativo da reprodução musical; 2) o termo "interpretação" não permite a sua aplicação a aspectos corporais, ou seja, mímico-gestuais do músico-intérprete; e 3) o termo performance não se confunde com o aspecto interpretativo e contemplativo da reprodução.

\section{7 - Considerações finais}

0 aspecto performativo da prática musical se manifesta principalmente na representação cênica, mímica e gestual no palco. Outrossim, abrange os elementos de ordem técnica que envolvem a sua execução com o instrumento e que sublinham determinados elementos musicais de uma composição. Sua função está em salientar conteúdos especificamente musicais, tornando-os, desse modo, mais claros para o espectador. Ao empregar técnicas miméticas, mímicas e gestuais, 0 intérprete as emprega como meio de sublinhar certos elementos intramusicais para o público espectador. Para tal, existe uma série de técnicas e elementos extramusicais, como as de representação cênica, nas quais, mesmo que apenas gestualmente, o músicointérprete se assemelha a um "mímico" ou "ator". Desse modo, nós nos aproximamos do conceito de embodiment como "presença física no palco", o qual, em sua versão profissional, inclui uma espécie de coaching 


\section{REPRODUÇÃO MUSICAL}

Designa a realização hic et nunc de uma composição musical com base em seu texto ou partitura. Como registro histórico, o texto representa a parte "objetiva" ou "objetivada" da composição (na medida em que este foi elaborado para servir à reprodução como base). A relação de texto e música é precária e paradoxal. Por isso, o texto não passa de um registro rudimentar da composição. Assim, pode se dizer que toda reprodução representa uma espécie de "atualização" de um "original" (cuja definição exige uma pesquisa em separado). Nessa tarefa, o músico-intérprete procede mimeticamente (ou seja, por mimesis ou ação mimética). Em tese, toda reprodução musical se dá por duas vias: a) pela interpretação, e b) pela performance. Tratando-se de um processo histórico, não existe uma reprodução que pudesse ser considerada "última" ou "definitiva".

\section{INTERPRETAÇÃO}

É atinente à "leitura" de um texto que o transforma novamente em parâmetros de som musical. "Leitura" + prática interpretativa $=$ "obra" ${ }^{24}$ no sentido de que esta precisa ser compreendida em forma e conteúdo, assim como em seus parâmetros de linguagem, contingenciados histórica e socialmente.

"Interpretação" designa, em música, a leitura singular de uma composição com base em seu registro que, representado por um conjunto de sinais gráficos, forma a "imagem do som". 0 intérprete decodifica os sinais gráficos, transformando-os de maneira mais fiel em parâmetros sonoros. Desse modo, "interpretar" está diretamente ligado à compreensão dos elementos que estruturam uma obra, como: altura, melodia, ritmo, harmonia, tonalidade e tempo musical. Outros elementos caracterizam a música como linguagem. Entre eles, estão a articulação, a pontuação, a forma e o sentido. Também o fraseado e a coesão ou coerência fazem parte desta categoria. Tudo isso demanda, de um lado, uma postura introvertida, voltada para a análise e a reflexão teórica (em sentido aristotélico de contemplação mais do que de ação), ao passo que, de outro lado, demanda a prática instrumental (ou seja, a prática interpretativa propriamente dita).

\section{PERFORMANCE}

É atinente à experiência viva, ao hic et nunc do palco, à gestualidade e a aspectos corporais do músicointérprete com relação ao modo e aos meios de sua apresentação com o instrumento. Os termos concerto, encenação, show e espetáculo remetem à performance como evento sociocultural.

A performance está sobretudo na elaboração dos elementos extramusicais da reprodução musical. Desta categoria fazem parte a gestualidade, a mímica e a destreza técnica do músico-intérprete ao instrumento (virtuosismo). Todos esses elementos são atinentes à corporalidade, ou seja, ao ato de "tocar" a música. Essencialmente extrovertidos, remetem à exteriorização de conteúdos já elaborados em etapas anteriores, mas que agora se engendram por outros meios que não os puramente musicais. Possuindo um forte caráter lúdico, também podem abranger os efeitos multimídia, assim como a produção musical e a visual. "Performar" significa, portanto, "atuar" e "transformar". Sua função está na interação com o público espectador, que não é percebido passivamente como mero "receptor" e sim, em sentido lato, também como "ator". Nesse processo, cada parte assume um determinado papel social que se estimula e se alimenta reciprocamente.

Ex.1. Esquema do trinômio de reprodução, interpretação e performance musical e sua fundamentação.

ou programa de treino psico-físico para o artista ou performer treinar sua memória, e para se preparar para determinadas situações de palco que demandam intenso estresse físico e emocional.

Grosso modo, trata-se de avaliar o que exatamente as artes cênicas e as performance arts têm a oferecer (ou a ensinar) às práticas interpretativas (disciplina que paradoxalmente não foi concebida como performance art). Nesse contexto, lembremo-nos novamente do postulado de ADORNO (2005, p.206, 237), segundo o qual "a música é mímica na medida em que determinados gestos resultam em som musical". Assim sendo, o modelo apresentado abre espaço para um suporte teórico em que o tão difundido conceito de performance emerge de fato fundamentado como uma nova especialização da área da música.

Também os conceitos de reprodução, interpretação e performance representam princípios distintos, onde cada campo pode constituir objeto de uma grande variedade de análises. Desse modo, o modelo proposto não está restrito ao gênero clássico-romântico. Dependendo do gênero e da linguagem musical em questão, pode se preferir uma ou outra categoria como ponto de partida para a análise. De qualquer forma, tanto a medida proporcional quanto a qualidade de cada elemento categorial vão se refletir diretamente no resultado final da reprodução (Kuehn, 2010, p.58, 112-113, 167-169). 
Finalizemos com a articulação das seguintes premissas:

1) o ciclo de criação de uma composição musical se fecha apenas com a sua reprodução (e não com a sua escritura);

2) por lhe faltar a reprodução musical propriamente dita, consideramos que a partitura representa o registro histórico da composição (e não a "obra em si");

3) de origem clássico-romântica, o conceito de "obra musical" é problemático e precisa ser redefinido;

4) também a relação de imagem, notação musical e som é problemática, revelando uma série de paradoxos;

5) antes de que possa ser reproduzida adequadamente, a composição precisa ser compreendida em seus mais diversos parâmetros e aspectos;

6) tendo como base as informações que os sinais transmitem através da imagem do texto, a composição é reproduzida por uma espécie de mimese ou ação mimética que a transforma novamente em som musical;

7) assim sendo, a essência da reprodução musical está em seu processo mimético do qual tanto o elemento interpretativo quanto 0 elemento performativo constituem princípios ativos;

8) para que uma reprodução musical se configure como performance, é indispensável a presença do público (ou seja, o ambiente deve ser mesmo o de uma performance);

9) embora toda reprodução individual seja peculiar e única em seus parâmetros sonoros e temporais, ela também se relaciona de alguma forma com as demais reproduções ou registros de uma mesma composição (na medida em que esta já pode ter acumulada um determinado número de interpretações, ou que pode ter sido objeto de controvérsias quanto à escolha de determinadas opções interpretativas);

10) ainda que - com relação à tradição clássicoromântica - predominem o elemento interpretativo e o decoro de uma ética rigorosamente normativa, nem por isso o aspecto performativo representa um elemento menos produtivo ou atrativo para o intérprete, o pesquisador ou o crítico musical;

11) desse modo, reprodução, interpretação e performance formam três categorias centrais do processo artísticomusical e não se confundem;

12) logo, o termo "reprodução musical" não deve ser tomado por sinônimo de interpretação ou de performance e sim como conceito abrangente que designa o momento em que uma composição é apresentada ou "tocada" musicalmente;

13) sendo assim, o conceito de reprodução musical se estende ao aspecto mimético, ao ato performativo, à interpretação, à execução, assim como ao funcionamento de regras internas e externas de uma apresentação musical no palco;

14) é com base nesses princípios e premissas que tanto 0 conceito de "prática interpretativa" quanto o de "práticas interpretativas" aumentam consideravelmente em sua abrangência;

15) por tudo isso, os elementos aqui relatados passam a engendrar um processo em que se migre de uma noção embasada quase que unicamente na interpretação para a de um processo artístico multiforme que inclui também os elementos extramusicais da reprodução.

\section{Referências}

ADORN0, Theodor W. Gesammelte Schriften (Obra completa). Digitale Bibliothek, v.97, CD-ROM. Berlim, Alemanha: Directmedia Publishing, 2003. . Zu einer Theorie der musikalischen Reproduktion: Aufzeichnungen, ein Entwurf und zwei Schemata. Nachgelassene Schriften. Editado por Henri Lonitz. Frankfurt a. Main, Suhrkamp [2001], 2005. . Towards a theory of musical reproduction: notes, a draft and two schemata. Editado por Henri Lonitz. Tradução de Wieland Hoban. Londres: Polity Press, 2006.

AQUINO, Felipe A. de. "Práticas interpretativas e a pesquisa em música: dilemas e propostas". In: Opus. Revista da Associação Nacional de Pesquisa e Pós-Graduação em Música (ANPPOM), n.9, dezembro de 2003, p.103-112. Disponível em: <http://www.anppom.com.br/opus/opus9/sumario.htm>, último acesso set. 2011.

AUSTIN, John Langshaw. How to do things with words. 2.ed. Cambridge: Harvard University Press, 1975.

BENJAMIN, Walter. "A obra de arte na época de suas técnicas de reprodução". Tradução de José L. Grünewald. In: Benjamin; Adorno; Horkheimer, Habermas. Os Pensadores. São Paulo: Abril Cultural, 1980, p.3-28.

BOENKE, Patrick. „Zur Rezeption der Schichtenlehre Heinrich Schenkers in der deutschsprachigen Musikwissenschaft nach 1945". In: Music Theory and Analysis Journal (GMTH), ano 2, ed.2, 2005.

"Zur österreichischen und deutschen Rezeption der Schichtenlehre Heinrich Schenkers". In:

EYBL; FINK-MENNEL (orgs.). Schenker-Traditionen. Viena: Böhlau, 2006, p.149-154.

DORIAN, Frederick. The history of music in performance. New York: Norton, 1942. 
DOURADO, Henrique A. Dicionário de termos e expressões da música. São Paulo: Editora 34, 2004.

EYBL, Martin (ed.). Die Befreiung des Augenblicks. Schönbergs Skandalkonzerte 1907 und 1908. Eine Dokumentation. Viena: Böhlau, 2004.

EYBL, Martin; FINK-MENNEL, Evelyn (orgs.). Schenker-Traditionen (org.). Eine Wiener Schule der Musiktheorie und ihre internationale Verbreitung. Viena: Böhlau, 2006.

FINK-MENNEL, Evelyn. "Schopenhauer, Freud, and the concept of deep structure in music". In: EYBL; (orgs.). SchenkerTraditionen. Viena: Böhlau, 2006, p.51-58.

FISCHER-LICHTE, Erika. Ästhetik des Performativen. Frankfurt a. Main: Edition Suhrkamp, 2004.

FREUD, Sigmund. "Entwurf einer Psychologie" (1895). In: Gesammelte Werke (Nachtrag). Texte aus den Jahren 1885 bis 1938. Frankfurt a. Main: Fischer, 1987, p.375-488.

GRASSL, Markus; KAPP, Reinhard (eds.). Aufführungslehre der Wiener Schule. Die Lehre von der musikalischen Aufführung in der Wiener Schule. Viena: Böhlau, 2002.

HETZEL, Andreas. "Das Rätsel des Performativen. Sprache, Kunst und Macht". In: Philosophische Rundschau, v.51. Tübingen: Mohr Siebeck, 2004, p.132-159.

KAPP, Reinhard. "Performance bei Arnold Schönberg und John Cage". In: GRASSL; KAPP (eds.). Aufführungslehre der Wiener Schule. Viena: Böhlau, 2002, p.455-468.

KOLISCH, Rudolf. Rudolf Kolisch. Zur Theorie der Aufführung. Ein Gespräch mit Berthold Türcke. In: METZGER; RIEHM (eds.). Musik-Konzepte, n.29/30. Munique: Edition Text + Kritik, 1983.

KUEHN, Frank M. C. "A prática interpretativa é uma arte mimética? - Acerca de mimesis e interpretação na Teoria da Reprodução Musical de Theodor Adorno". In: Anais. Segundo Simpósio de Musicologia da Universidade Federal do Rio de Janeiro (UFRJ). Rio de Janeiro: Editora UFRJ, 2012.

. "Heinrich Schenker e 'A Arte da Performance': uma análise de incongruências resultantes da sua tradução e uma proposta de resolução". In: Anais. XXI Congresso da Associação Nacional de Pesquisa e Pós-Graduação em Música (ANPPOM). Uberlândia: Universidade Federal de Uberlândia (UFU), 2011, p.1311-1317.

A teoria da reprodução musical de Theodor Adorno e o legado da tradição vienense: uma introdução. Rio de Janeiro: PPGM, CLA, Universidade Federal do Estado do Rio de Janeiro (UNIRIO), 2010. Tese de Doutoramento. Disponível em: <http://www.dominiopublico.gov.br/pesquisa/DetalheObraForm.do?select_action=Ctco_obra=203127>, último acesso junho 2011.

- Antonio Carlos Jobim, a Sinfonia do Rio de Janeiro e a Bossa Nova: caminho para a construção de uma nova linguagem musical. Rio de Janeiro: PPGM, CLA, Escola de Música da Universidade Federal do Rio de Janeiro (UFRJ), 2004. Dissertação de Mestrado.

SCHENKER, Heinrich. The Art of Performance. Tradução de Irene Schreier Scott. Editado por Heribert Esser. Oxford: Oxford University Press, 2000.

SCHILLER, Friedrich. "Vom Pathetischen und Erhabenen". In: Schriften zur Dramentheorie. Stuttgart: Philipp Reclam jun., 2009.

SCHÖNBERG, Arnold. Style and Idea. Berkeley: University of California Press, 1984.

. Stil und Gedanke. Leipzig: Philipp Reclam jun., 1989.

WAGNER, Richard. Über das Dirigieren. Darmstadt: Wissenschaftliche Buchgemeinschaft e.V., 1953, p.69-140.

\section{Bibliografia complementar}

AMATO, Rita F. "Voz cantada e performance". In: Lima (org.). Performance \& interpretação: uma prática interdisciplinar. São Paulo: Musa, 2006, p.65-79.

APRO, Flávio. "Interpretação musical". In: Lima (org.). Performance \&t interpretação: uma prática interdisciplinar. São Paulo: Musa, 2006, p.24-37.

BORÉM, Fausto. "Metodologias de pesquisa em performance musical no Brasil: tendências, alternativas e relatos de experiência". In: Ray (org.). Performance musical e suas interfaces. Goiânia: Editora Vieira, 2005, p.13-38.

; LAGE, Guilherme M.; VIERA, Maurilio N.; BARREIROS, João P. "Uma perspectiva interdisciplinar da visão e do tato na afinação de instrumentos não-temprerados". In: Lima (org.). Performance \& interpretação: uma prática interdisciplinar. São Paulo: Musa, 2006, p.80-101.

BRinkMANN, Reinhold; WOLFF, Christoph (eds.). Driven into Paradise: the musical migration from Nazi-Germany to the United States. Berkeley: University of California Press, 1999.

CHUEKE, Zélia. "Estágios de escuta durante a preparação e a execução pianística na visão de seis pianistas de nosso tempo". In: Ray (org.). Performance musical e suas interfaces. Goiânia: Editora Vieira, 2005, p.39-64.

CLARKE, Eric. "Understanding the psychology of performance". In: Rink (org.). Musical performance. Cambridge: University Press, 2006, p.59-74. 
DAVIDSON, Jane. "Developing the ability to perform". In: Rink (org.). Musical performance. Cambridge: University Press, 2006, p.89-101.

DUNSBY, Jonathan. "Performers on performance". In: Rink (org.). Musical performance. Cambridge: University Press, 2006, p.225-236.

GANDELMAN, Salomea. "A relação análise musical / performance e a pesquisa em práticas interpretativas no Programa de Pós-Graduação em Música da UNIRIO". In: Anais. XIII Encontro Nacional da ANPPOM, 2001. Belo Horizonte: UFMG, 2001, v.2. p.489-495.

. "Uniformidade e diversidade na execução musical". In: Anais. VIII Encontro Nacional da ANPPOM, 1996, João Pessoa: Universidade Federal de Paraíba, 1996, v.1, p.211-217.

GERLING, Cristina C.; GUSMÃO, Pablo S. "0 tempo e a dinâmica na construção de uma interpretação musical". In: Ray (org.). Performance musical e suas interfaces. Goiânia: Editora Vieira, 2005, p.65-94.

Lima, Sonia A. de (org.). Performance \&t interpretação: uma prática interdisciplinar. São Paulo: Musa 2006.

. "0 virtual e o real da interpretação". In: Lima (org.). Performance \& interpretação: uma prática interdisciplinar.

São Paulo: Musa, 2006, p.48-64.

" "Performance: investigação hermenêutica nos processos de interpretação musical". In: Ray (org.). Performance musical e suas interfaces. Goiânia: Editora Vieira, 2005, p.95-118.

; APRO, Flávio; CARVALHO, Márcio. "Apresentação". "Performance, prática e interpretação musical". In: Lima

(org.). Performance \& interpretação: uma prática interdisciplinar. São Paulo: Musa, 2006, p.11-23.

Ray, Sonia (org.). Performance musical e suas interfaces. Goiânia: Editora Vieira, 2005.

"Os conceitos de EPM, potencial e interferência inseridos numa proposta de mapeamento de estudos sobre performance musical". In: Ray (org.). Performance musical e suas interfaces. Goiânia: Editora Vieira, 2005, p.39-64.

REID, Stefan. "Preparing for performance". In: Rink (org.). Musical performance. Cambridge: University Press, 2006, p. 102112.

Rink, John (org.). Musical performance. Cambridge: University Press, 2006 [2002].

. "Analysis and (or?) performance". In: Rink (org.). Musical performance. Cambridge: University Press, 2006, p.35-58.

ZANON, Fábio. "Música como profissão". In: Lima (org.). Performance \&t interpretação: uma prática interdisciplinar. São Paulo: Musa, 2006, p.102-127.

\section{Notas}

1 "Das ganze Reich der Phantasie und Geschichte, Vergangenheit und Zukunft stehen ihrem Wink zu Gebot". Salvo indicação em contrário, a tradução das citações é do autor.

2 Entre aspas porque não faz parte do escopo deste ensaio discutir a legitimação de quem estava representando a academia como instituição científica.

3 Sobre as atividades de interação de Koellreutter com figuras importantes da MPB, vide também KUEHN (2004, p.23-29).

4 "The mere fact that our notation hardly represents more than neumes should lead the performer to search for the meaning behind the symbols" (SCHENKER, 2000, p.5).

5 Em ordem crescente: 1) "dass seit Beethoven hinsichtlich der Behandlung und des Vortrages der Musik eine ganz wesentliche Veränderung gegen früher eingetreten ist"; 2) "von dem Orchestervortrag unserer klassischen Instrumentalmusik"; e 3) "eine öffentliche Aufführung der Overtüre zu Egmont" (In: WAGNER, 1953, p.78, 97, 110).

6 Para mais informações sobre a recepção de Schenker nos EUA, vide: FINK-MENNEL (2006) e EYBL; FINK-MENNEL (2006). Sobre a recepção de Schenker na Europa consultar: BOENKE (2005).

7 "I claim, performances have always taken a shape that has nothing to do with a true reproduction. Because what ought to be known in order to perform a sonata by Beethoven is not known, the musical world found it easy to assign a role to reproduction in music that is in appalling contrast to its real origins" (SCHENKER, 2000, p.4).

8 "It must be admitted that in the period around 1900 many artists overdid themselves in exhibiting the power of emotion they were capable of feeling [...] artists who believed themselves to be more important than the work - or at least than the composer" (SCHÖNBERG, 1984, p.321).

9 "Ein kluger Ausführender, einer, der wirklich 'ein Diener am Werk' ist, einer, dessen geistige Beweglichkeit der eines Musikdenkers ebenbürtig ist solch ein Mann wird wie Mozart oder Schubert oder andere verfahren" (SCHÖNBERG, 1989, p.116).

10 "The highest principle for all reproduction of music would have to be that what the composer has written is made to sound in such a way that every note is really heard" (SCHÖNBERG, 1984, p.319).

11 Para ilustrar a temática dos manuscritos de Schönberg, segue-se uma transcrição dos títulos na ordem em que aparecem na coletânea de ensaios, intitulada Style and Idea: "Para um tratado de performance" (1923/24); "As formas atuais de performance da música clássica" (1948); "0 futuro dos instrumentos da orquestra" (1924); "Instrumentos musicais mecânicos" (1926); "Instrumentação" (1931); "0 futuro da ópera" (1927); "Ópera: aforismos" (1930); "Indicações de performance" (1923); "Dinâmica musical" (1929); "Sobre indicações de metrônomo" (1926); "Transposição" (1923); "Vibrato" (1940); "Fraseado" (1931); "A redução moderna de piano" (1923); "Sobre notação" (1923); "Notação pictórica" (1923); "Revolução-evolução, notação (acidentes)" (1931) e "A nova notação dos doze sons" (1924) (SCHÖNBERG, 1984, p.319-362). 
12 Nascido Friedrich Deutsch, adotou, ao se exilar nos EUA, o nome de Frederick Dorian. "Dorian-Deutsch [sic] tinha estudado com [Anton] Webern", anotou SCHÖNBERG $(1984$, p.484) num de seus ensaios. Além de ter estudado regência e teoria da composição com Webern, Dorian estudou piano com Eduard Steuermann e musicologia com Guido Adler (ADORNO, 2005, p.333-334; KUEHN, 2010, p.44-46).

13 Já existe uma quantidade considerável de estudos sobre a influência de Walter Benjamin em Adorno. Embora este represente um aspecto que não deve ser subestimado, mas não pôde constituir parte do escopo deste ensaio. Mais informações acerca do ensaio de Benjamin em (último acesso dez. 2010):

http://webcache.googleusercontent.com/search?q=cache:bOHsTF5KOSkJ:encyclopediaworldart.wordpress.com/2010/02/12/walter-benjamin-daskunstwerk-im-zeitalter-seiner-technischen-reproduzierbarkeit/+Benjamin+Zeitalter+derEtcd=4\&thl=pt-; e http://de.wikipedia.org/wiki/Das_Kunstwerk_im_Zeitalter_seiner_technischen_Reproduzierbarkeit.

14 Edição que serviu também de referência para minha pesquisa de tese de doutoramento (KUEHN, 2010).

15 "Auf welche Weise man vom Werke ablese, welche Freiheit es dem Interpreten lässt, der es als Werk interpretiert - das zu erforschen scheint die zentrale Aufgabe einer Theorie der Reproduktion, die freilich, als Theorie, nicht durchdringen könnte, was unlöslich verquickt das Gebilde in seiner Fülle, den Nachbildner als ganzen Menschen umschlossen hält" (ADORNO, 2003, v.19, p.441). Observação: Nachbildner é literalmente aquele que recria a partir de uma imagem, ou seja, o intérprete que recria uma determinada obra musicalmente com base em sua partitura.

16 Examinando-se bem, a relação entre o conceito de imitação (nachbilden, imitatio, mimesis) e prática interpretativa já está estabelecida na própria denominação da teoria de Adorno, onde o prefixo "re" em "reprodução" evidencia que uma composição é apresentada mimeticamente. Com efeito, o conceito de mimesis aplicado à reprodução e à interpretação musical ocupa um espaço privilegiado das anotações que compõem o material da sua teoria.

17 Certamente seria mais coerente traduzir o título do evento por "Adorno e a prática interpretativa", já que também Adorno explora, com exceção do elemento mímico-gestual, mais o aspecto interpretativo da prática musical. Desse modo, Adorno segue claramente a tradição vienense.

18 Contando-se apenas os imigrantes representativos, sabe-se que o número ultrapassa o milhar. 0 êxodo para os Estados Unidos mobilizou milhares de cientistas, intelectuais e artistas, entre judeus e não judeus. Segundo estudos recentes, somente o número de músicos que emigraram para os Estados Unidos varia, dependendo da fonte, entre 500 e 1,5 mil - um número sem dúvida considerável quando levamos em conta que via de regra se tratava de pessoas altamente gabaritadas (cf. BRinkMANN; WOLFF, 1999).

19 "Die Beziehung von Mimik und Musik, zentral, wird offenbar in der Sphäre der Reproduktion [...] Musik ist mimisch insofern, als bestimmte Gesten [...] musikalischen Klang [ergeben]. Musik ist gewissermassen die akustische Objektivation des Mienenspiels, die von diesem vielleicht überhaupt erst historisch sich getrennt hat" (ADORNO, 2005, p.206, 237).

20 Para mais informações sobre a citada composição de Cage, consultar: <http://en.wikipedia.org/wiki/4.33>, último acesso jan. 2011.

21 "Interpretation is necessary, to bridge the gap between the author's idea and the contemporary ear, the assimilative powers of the listener at the time in question" (Schönberg, 1984, p.328).

22 "Basically, a composition does not require a performance in order to exist. Just an imagined sound appears real in the mind, the reading of a score is sufficient to prove the existence of the composition. The mechanical realization of the work of art can thus be considered superfluous" (SCHENKER, 2000, p.3).

23 "Embodiment is the process of uniting the imaginary separation between body and mind. It is the process within psychophysical training [ou coaching] that generates 'presence' on stage" (disponivel em: <http://en.wikipedia.org/wiki/Process_of_embodiment_\%28physical_theatre\%29>, último acesso set. 2011).

24 Termo aqui empregado apenas provisoriamente. Passando-se do âmbito clássico-romântico, o conceito de "obra musical" se torna problemático e precisa ser redefinido (ou mesmo abandonado).

Natural de Berlim, Alemanha, Frank Michael Carlos Kuehn estudou violão, guitarra elétrica e percussão. Músico, participou de diversas formações musicais. Atraído pela música brasileira, emigrou para a cidade do Rio de Janeiro, onde passou a atuar em recitais de música erudita e popular, no magistério e na pesquisa acadêmica. Graduado em Educação Musical pela UFRJ, é Mestre em Música pela UFRJ, e Doutor em Música pela UNIRIO. Atualmente, sua pesquisa enfoca questões relativas à prática musical com seus desdobramentos estéticos e filosóficos para a teoria da interpretação e da performance. Definida em áreas de conhecimento, sua pesquisa contempla: interpretação musical, teoria da interpretação, teoria da performance, teoria crítica da arte e da sociedade, e filosofia da música. 